\title{
Summary of Application of Fuzzy Mathematics in Construction Project Management
}

\author{
Dongyou Tong, Yueming Wang \\ School of Civil Engineering and Architecture, Southwest University of Science and Technology, Mianyang, China \\ Email: 347940095@qq.com
}

How to cite this paper: Tong, D.Y. and Wang, Y.M. (2021) Summary of Application of Fuzzy Mathematics in Construction Project Management. World Journal of Engineering and Technology, 9, 407-422. https://doi.org/10.4236/wjet.2021.93028

Received: May 26, 2021

Accepted: July 18, 2021

Published: July 21, 2021

Copyright (อ 2021 by author(s) and Scientific Research Publishing Inc. This work is licensed under the Creative Commons Attribution International License (CC BY 4.0).

http://creativecommons.org/licenses/by/4.0/

(c) (i) Open Access

\begin{abstract}
Construction project management is an important aspect of civil engineering construction. How to use scientific and efficient methods to effectively manage construction projects is the focus of construction project development under the current situation. This article discusses the application of fuzzy mathematics in construction project management. The study found that in the process of construction project management, it was found that a single fuzzy mathematical method was difficult to adapt to the current complex and changeable construction projects. Combining fuzzy mathematics with other management methods and computer applications can better simplify complex things, reduce human subjectivity, increase calculation speed, and achieve a combination of qualitative and quantitative research; selection of optimization schemes and risk assessment, etc. All have a good effect, and can better deal with possible or uncertain things and emergencies in the process of project management. At the same time, combining fuzzy mathematics with heuristic algorithms or meta-heuristic algorithms can make research more objective, improve management efficiency and calculation speed.
\end{abstract}

\section{Keywords}

Fuzzy Mathematics, Project Management, Civil Engineering

\section{Introduction}

With the advancement of science and technology and the continuous development of society, the contemporary project environment has the characteristics of fast speed, rapid change, low cost, increased complexity and increased uncertainty. The relevant personnel of construction project management are facing huge challenges, requiring them to have high scientific management concepts, methods, management means and matching engineering technology. It is a chal- 
lenge under the new situation to adopt scientific and effective methods to meet the high standards and requirements of construction engineering management. Construction project management involves the management of the whole process of the project, and its connotation refers to the realization of the cost, schedule and quality objectives of the project through project planning and project control from the beginning of the project to the completion of the project [1]. In the whole life cycle of a project, there is some ambiguity in the contents of management at different stages. For uncertain, inaccurate and inaccurate events, the traditional methods may lead to inaccurate or inefficient results. Scholars such as Abdul-Rahman, Wang Kaibao and others [2]-[13] combine fuzzy mathematics with construction project management, and use fuzzy mathematics methods to judge, evaluate and make decisions on the research objects, so as to form a more effective management and decision-making system.

Due to the limitations of classic mathematics, in 1965, Professor LAZadeh of the University of California published two groundbreaking papers entitled: "Fuzzy Sets" and "Fuzzy Sets and Systems", which laid the foundation for fuzzy set theory and application research. It marked the birth of fuzzy mathematics [14] [15] [16] [17]. Fuzzy mathematics theory is not only a new mathematical theory, but also a new mathematical tool, mainly to solve some "fuzziness" phenomena. After decades of development, fuzzy mathematics has opened up its application field in the direction of construction engineering project management. The application of fuzzy mathematics theory has also obtained rich research results, and it has solved some problems that cannot or are difficult to solve with classical mathematical methods. We showed a very gratifying prospect [18] [19].

It is very useful to explore the application of fuzzy mathematics in engineering management. What we have to do now is to maximize the application effect of fuzzy mathematics in construction project management, continue to promote the use of fuzzy mathematics in engineering management, and continuously improve related technologies. Improve management efficiency and the quality and economic benefits of civil construction projects.

\section{Application of Fuzzy Mathematics in Risk Management of Construction Projects}

Due to the long construction period, complex technology, large investment and other characteristics of engineering projects, there are many uncertain factors that affect the development of the project toward the established goal, so there are many risks in the construction process of the engineering project. Risk refers to the uncertainty between the purpose of production and the results of labor, which has objectivity, universality, inevitability, identifiability, controllability, loss, uncertainty and sociality. For construction project management, risk refers to the possible uncertain factors that may affect the realization of project goals. In the process of construction project risk management, by studying the application of fuzzy mathematics in construction project risk management, we explore 
better methods of planning, organization, leadership, coordination and control, and provide a basis for risk decision-making.

\subsection{Application of Fuzzy Mathematics in Project Evaluation}

Traditional project evaluation methods mainly include: net present value, internal rate of return, investment payback period, equal annual value, etc. However, because the project has attributes such as one-off, the risk of the project is based on itself, and the risk cannot be excluded from the project. In order to consider the impact of project risk on project evaluation, sensitivity analysis and probability analysis are introduced. Due to the difficulty of data collection, the ignorance of the relevance of risk factors, the inability to deal with qualitative issues, and the neglect of risk connotations, both have shortcomings.

Yang, Q [20] In the process of risk analysis of highway projects, in order to avoid the subjective one-sided identification weight and the measurement of fuzzy factors, the fuzzy comprehensive evaluation method and the analytic hierarchy process are combined to construct the fuzzy analytic hierarchy process model. Through the establishment of a highway engineering risk factor analysis index set, qualitative analysis and quantitative analysis are combined to make subjective evaluation objective and solve the problem of measuring fuzzy factors.

Post-project evaluation generally uses methods such as statistical prediction and comparison, but it can only be used as a qualitative evaluation, not a quantitative evaluation. Zhu, H. [21] In order to achieve quantitative evaluation in the post-project evaluation, fuzzy mathematics was introduced into the post-project evaluation, and the difficulty of quantitative evaluation was solved by establishing a fuzzy comprehensive evaluation model and using the fuzzy mathematics evaluation model.

Xie Xiaohong [22] established an evaluation model by introducing fuzzy mathematics membership function: decomposing the project, identifying risk factors, determining the probability distribution or membership function of each factor and standardizing it, and synthesizing monetary factors or non-monetary factors according to their weights. Synthesize the total joint distribution of each evaluation plan. Taking fuzzy mathematics evaluation method as the core, by simplifying the evaluation process, using expert method to evaluate unquantified factors, it provides a multi-objective evaluation method for project evaluation. It solves the problems of risk factors that are difficult to accurately describe and quantify in the risk evaluation of the traditional probabilistic consequence model.

\subsection{Application of Fuzzy Mathematics in the Process of Risk Management}

Project risk management can be divided into four steps: identification, estimation, evaluation, control and management. As the first step of risk management, risk identification is that the basis of risk management is the premise of risk es- 
timation. Commonly used risk identification methods include: brainstorming method, Delphi method, etc., which mainly rely on human subjective judgment in qualitative analysis, and lack objectivity. However, quantitative analysis is lacking in traditional methods.

Zhong, Y. [23] combines fuzzy mathematics with system dynamics, and proposes a fuzzy system dynamics method with theoretical innovation and practicality, which quantitatively analyzes the uncertainty of the project. Analyze the uncertainty in the construction project from an overall perspective, so as to provide a more systematic management strategy. Wang, X. [24] established a calculation model based on interval numbers by using analytic hierarchy process and fuzzy mathematics theory. The interval membership function and the weight of each factor are quantified, and the relative advantage of the interval matrix is analyzed. A risk assessment method for water gushing and water gushing intervals in karst tunnels is proposed. On this basis, the concept and calculation form of the risk assessment model are introduced, and the risk environment, construction factors and feedback information are analyzed. Meng, G. [25] Based on the evaluation method of analytic hierarchy process and fuzzy mathematics, the risk assessment of deep foundation pit construction was studied. The results show that it is a very good risk level assessment method. Xu, S. [26] used Monte Carlo method and fuzzy mathematics to study the risk management of construction projects, combined qualitative analysis and quantitative research, and proposed a new solution.

Geng, D. [27] combines fuzzy mathematics with analytic hierarchy process, uses fuzzy risk judgment matrix to realize the risk occurrence probability and risk loss of risk factors, and comprehensively considers the risk occurrence probability and the importance of risk loss. It avoids the disadvantages of too many factors and the difficulty in assigning weights, and avoids the one-sidedness of single-factor decision-making and decision-making errors caused by human subjective consciousness. It can make scientific and accurate judgments for the selection of the construction plan. Chang Fei [28] uses fuzzy mathematics and analytic hierarchy process to establish a model that can more accurately determine the risk weights, and rank all risks as a whole, and can make a more reasonable and accurate evaluation of the risks of international projects. It solves the problem that the analytic hierarchy process is too general and the monte Carlo conditions are too strict, and the risks of international projects cannot be comprehensively analyzed.

Zheng Zhanfei [29] used fuzzy mathematics to construct a fuzzy comprehensive evaluation model of risk influencing factors: setting the domain of theory, determining the fuzzy matrix, and determining the weight vector. Through the iterative algorithm of the analytic hierarchy process, the importance of each factor is determined, and the subjective judgment of experts is used to determine. Using fuzzy comprehensive evaluation, combining subjective judgment with objective quantitative analysis, improves the problem of single and transitional de- 
pendence on expert judgment in risk identification.

Wang Yuan et al. [30]-[36] used fuzzy comprehensive evaluation method, fuzzy gray theory comprehensive evaluation method, fuzzy analytic hierarchy process and other methods to analyze and evaluate each risk factor of the project, and better considered the uncertainty in risk evaluation. And ambiguity, realizing quantitative analysis and determining the degree of risk impact, providing effective measures for project risk management. At the same time, Xie Meng [37] and Feng Guangyi [38] also conducted risk analysis in construction project management for agent construction units and auditing units, and provided references for different entities to reduce the losses caused by risks in the process of construction project management.

\section{Application of Fuzzy Mathematics in Safety Management of Construction Projects}

With the continuous improvement of the construction project management system, safety accidents still occur from time to time. For example, construction sites such as the collapse of tower cranes, workers falling from height, and collapse of foundation pits occur at construction sites such as Jining in Shandong and Guangling District in Yangzhou. Due to the high risk of engineering construction, each accident is accompanied by casualties. Therefore, in order to prevent construction safety accidents, it is necessary to strengthen on-site safety management and build an effective construction safety evaluation system.

Fan, Z. [39] analyzed the fuzzy membership degree of the influencing factors of the negative impact of the groundwater environment on the tunnel project, and gave MATLAB software for comprehensive evaluation and analysis. It is scientific to realize the comprehensive evaluation of the negative impact of groundwater on the tunnel project in advance to ensure the safety and stability of the tunnel project.

Zhang Chuquan [40] used fuzzy mathematics comprehensive evaluation method to construct a safety evaluation system: determine the set of evaluation objects, establish the evaluation level set, determine the weight of evaluation index, determine the membership function, establish the single-factor evaluation matrix, and calculate the first-level fuzzy comprehensive evaluation of each index result. Construction safety management adopts the principle of maximum degree of membership of fuzzy mathematics to evaluate the safety level of construction projects, the qualifications of construction units, and on-site management, and take corresponding safety measures to ensure the safe progress of the project.

Guo Jinging et al. [41] [42] [43] [44] [45] conducted corresponding research on construction safety by combining fuzzy mathematics and other methods, and constructed a safety evaluation system, which provided a basis for construction safety management to prevent safety accidents. Zan Yanguo [46] uses the method of fuzzy identification to establish a mathematical model of fuzzy identification of safety hazards in construction engineering. On this basis, using a large 
amount of construction engineering data, through real-time and continuous information collection, the corresponding feature set is extracted to identify the safety state of the project, and then realize the identification and prevention of engineering safety hazards. It solves the problem of multiple and difficult to identify safety hazards in construction projects.

\section{Application of Fuzzy Mathematics in Bidding of Construction Projects}

The bidding system is a form of transaction for owners to find economical and qualified agent construction units as well as agent construction units to undertake project business. Through the bidding of engineering projects, in order to win in the fierce market competition, the agent construction unit analyzes various factors that affect the bidding decision before bidding for the project, seeks suitable bidding strategies and methods for comprehensive analysis and evaluation, and then determines the final reasonable bidding strategy and quotation. In this analysis and evaluation process, most of the factors are vague. Because the evaluation of the factors is vague, the evaluation process and results are also vague, and it is difficult to accurately determine the degree of their influence on the bid price.

Using fuzzy mathematics evaluation method to analyze the bidding risk of construction projects can comprehensively and scientifically evaluate bidding projects, provide a scientific basis for contractors' bidding decisions, and ensure the interests of bidders themselves.

\subsection{Application of Fuzzy Mathematics in Bidding Decision}

In the bidding process, there are many factors that affect bidding. Only by mastering the correctness and predictability of the bidding quotation strategy and method can it be possible to win the bid. Fuzzy mathematics provides mathematical language and quantitative methods for fuzzy quantity problems, and provides a powerful tool for bidding decision-making.

Wang, W. [47] uses the fuzzy evaluation method of fuzzy theory set to comprehensively evaluate the engineering bidding system, selects the best plan from multiple alternatives, and provides decision support for the company's bidding. Li, D. [48] through the analysis of representative factors in the decision-making of bidding opportunities, proposed a quantitative method between the objects and factors in the bidding of engineering projects. Applying fuzzy mathematics to bid evaluation provides a basis for contractors to make reasonable decisions.

Li Dan [49] used fuzzy mathematics to construct a fuzzy evaluation model with a comprehensive evaluation method: the determination of the bid price factor set, the determination of the weight of each factor, the establishment of the comment set, the establishment of the membership relationship, the establishment of the fuzzy evaluation matrix, the fuzzy comprehensive evaluation, the determination of the evaluation level and Bidding quotation decision, quantita- 
tive analysis of the target and multiple influencing factors through the model. Under the premise of analyzing the cost, profit and other factors of the agent construction unit, conduct induction, deduction and reasoning to obtain the pros and cons of the agent construction unit's bidding, so as to obtain reasonable profits and provide decision-making for the bidding unit's bidding.

Liu Erlie, Wang Zhenxian and others [50] [51] [52] [53] used fuzzy mathematics, fuzzy logic, fuzzy comprehensive evaluation and other methods to comprehensively and scientifically evaluate bidding conditions, and use all influencing factors as a system to study and make qualitative indicators more objective and reasonable. Make the bid quotation more reasonable and more efficient and increase the bid winning rate.

\subsection{Application of Fuzzy Mathematics in Tender Evaluation}

The bidding not only regulates the construction market and promotes market competition, but also improves investment efficiency and saves investment for owners. The reasonable low price evaluation method, the lowest price evaluation method, and the comprehensive evaluation method used in traditional bid evaluation are expert scoring methods, and the highest score is the first winning bidder. The above methods have their own advantages and disadvantages, because scoring is artificially highly subjective.

Peng Hong [54] and others adopted fuzzy analytic hierarchy process by introducing fuzzy mathematics, and clearly reflected the relationship between various related factors through the hierarchical structure, so that decision makers could logicalize complex issues. Through the improvement of the comprehensive bid evaluation method, reasonable index weights are determined, and the scores of the candidate units are ranked by establishing the mathematical model of AHP and fuzzy mathematics, and the winning unit is finally determined.

\section{Application of Fuzzy Mathematics in Construction Project Cost}

Quickly estimating project cost is also one of the hot spots in the field of project management research, and it is one of the main factors that affect project construction throughout the project construction. Cost is inseparable at every stage in the life cycle of the project. In the decision-making stage, there are investment estimates, preliminary design and technical design stages, budget estimates, construction drawing budgets at the construction drawing design stage, and base bids or maximum prices at the bidding stage. And the bidding quotation, the intermediate settlement in the construction stage, and the completion settlement and final accounts in the completion acceptance stage. At the current stage, the project cost is estimated by using the comprehensive unit price method, and the project estimate price is obtained based on the relevant indicators, lists, quotas and market prices. At the present stage, due to the over-generalization of inventory pricing standards, there are objectively many imperfections in the method. 
The compilation process is relatively accurate and flexible, but to a certain extent, it is time-consuming and requires higher experience for practitioners. Therefore, the rapid and accurate estimation of the cost is of great significance to enterprise investment decision-making, cost control, and fund raising.

Wang, C. [55] used entropy and fuzzy analytic hierarchy process to study the comprehensive evaluation of water conservancy and hydropower project life cycle cost control. Standardize and objectify the evaluation indicators through information entropy, and combine with the subjective weight determined by the analytic hierarchy process to ensure the objectivity of the evaluation model. The results show that this method has achieved good results in cost control evaluation.

Zhang Chunsheng [56] uses fuzzy mathematics methods, based on a set of built projects, uses fuzzy mathematics theory to quantitatively determine the similarity between the built projects and the proposed projects, establishes the corresponding mathematical model, determines the fuzzy relationship coefficients, and calculates Weighted Hamming closeness to calculate the price of the proposed project, and finally check the calculation with the built project. When performing weighted Haiming closeness, the calculation result is more accurate only when the selected similar samples are reasonable. Research shows that its accuracy can be controlled within 5\%. The model calculation method combines expert analysis to determine the weight and other data processing modes. It does not need to calculate the engineering quantity, and does not need to query the estimated budget quota. It only needs to input the basic characteristics of the proposed project into the compiled software to quickly To get the total cost, this method saves trouble and time.

Han Minglun et al. [57]-[64] used fuzzy neural networks, fuzzy exponential smoothing and other methods to establish a model and process similar to the above. Both are based on the built projects and calculate the cost of the proposed project through fuzzy mathematics. Provide convenience for enterprises to make investment decisions quickly.

\section{Application of Fuzzy Mathematics in Contract Management of Construction Projects}

The contract serves as the contact hub between the owner, the agent construction unit and the third party, and it is also for the purpose of realizing the construction project objectives in accordance with the plan to bind them to each other and protect each other's rights and interests. In the process of project construction, the contract runs through and plays a role in controlling and guaranteeing the implementation of the project. If the contract is not well managed, it will lead to many disputes, and disputes will eventually lead to out of control of investment. That is, good contract management is very necessary to improve investment efficiency. Zhao Hebin [65] and others analyzed the problems in the practice of construction project contract management by using fuzzy mathematics methods, proposed corresponding control measures, established an internal 
contract management system, and formed a more effective management and decision-making system for construction project management. In order to promote the construction project contracting parties to properly and completely perform the construction project contract.

\section{Application of Fuzzy Mathematics in Other Aspects of Construction Project Management}

With the deepening of people's understanding of different directions in engineering management, many researchers apply fuzzy mathematics to other aspects of construction project management to make construction project management more efficient, while also improving quality, schedule and saving costs.

\subsection{Application of Fuzzy Mathematics in Engineering Claim}

Li Xuwei [66] put forward the theory of applying fuzzy mathematics to the rapid prediction of engineering claims by systematically analyzing the process of engineering claims and the relationship between the related parties of the claims, and constructed the corresponding prediction models. This model mainly applies the basic principles of fuzzy mathematics to the prediction of engineering claims, makes full use of the evaluation information of characteristic factors of typical engineering events, establishes an engineering claim prediction model, and proposes a calculation method of closeness to better reflect the number of engineering events. The similarity between the project to be constructed and the project to be constructed are quantitatively studied and compared, so as to quickly predict the project claim and the value of the claim value that the project to be constructed may encounter. This model can quickly analyze and identify the claim risk before the implementation of the project, and can improve the claim risk identification ability and prevention awareness of the construction parties during the project implementation process, and reduce the occurrence of claim incidents.

\subsection{Application of Fuzzy Mathematics in Project Settlement}

Bian Yanbin [67] used the risk breakdown structure method to identify the risk of project settlement disputes, and proposed a risk evaluation method based on the combination of analytic hierarchy process and fuzzy mathematics theory, established a set of risk factors and comment sets for project settlement disputes, and determined The weight of each factor and the evaluation matrix construct a fuzzy evaluation model. Realize the combination of sexual analysis and quantitative analysis, make subjective estimation objective, and provide reference for actual project settlement dispute risk evaluation decision.

\subsection{Application of Fuzzy Mathematics in the Objective of Engineering Project}

Xu Fangzhou [68] uses the multi-attribute utility function decision theory to 
obtain the maximum utility of the three goals at a certain risk level, and introduces the principle of fuzzy mathematics to give a fuzzy representation of the duration and direct cost of each process to establish an optimization Model, and use genetic algorithm to simulate and analyze the two stages to provide decision makers with ideal planning arrangements.

$\mathrm{Wu}$ Peng [69] introduced the theory of multi-attribute utility function into engineering quality control and established a quality control model that considers the cost of construction period. On the basis of network planning technology, using genetic algorithm to solve the model can get the most satisfactory decision plan and multiple approximately satisfactory alternatives have practical value to solve the contradiction between construction period cost and quality control. At the same time, a fuzzy comprehensive evaluation method of engineering quality is established on the basis of fuzzy set theory. This method can meet the requirements of multi-factor and multi-level evaluation. It not only considers all influencing factors, but also uses different weight coefficients for each factor in the calculation to highlight the important ones. The evaluation project retains all the evaluation information at all levels, and the quantitative results can well reflect the actual situation.

Deng Dexue [70] used fuzzy causality analysis to establish an optimization model for engineering quality improvement to improve the quality of construction projects. The fuzzy causality analysis model can objectively and quantitatively improve the quality of the project, find out the content to be improved comprehensively, and scientifically improve the quality of the project. Through the use of quantitative analysis of causality analysis to ensure the scientific nature of quality improvement, the method of quality improvement is more scientific and objective. Reduce non-specific and non-objective problems arising from qualitative improvement of quality. It solves the problems of qualitative analysis and quantitative analysis in my country's current construction engineering quality improvement.

Song Yang [71] systematically conducted theoretical research on residential project construction quality management, quality control, and quality management assurance system by comparing the status quo of residential project quality management at home and abroad. The basic knowledge of fuzzy mathematics is applied to the quality management of residential projects, and a mathematical model of fuzzy evaluation of residential project quality is established to comprehensively evaluate the quality of the project. The results show that it can objectively and quantitatively reflect the quality of the project to provide a more scientific and objective basis for the completion and acceptance of residential projects.

Liu Ze [72] used fuzzy mathematics to study the uncertainty of construction period of construction projects. Taking the satisfaction and reliability of the construction unit for the optimized construction period as the optimization goal, a mathematical optimization model of the construction schedule under resource- 
constrained conditions is established, and the construction schedule is optimized using evolutionary algorithms. Results Table This method has high effectiveness and feasibility when dealing with fuzzy resource-constrained construction projects. It can not only meet the construction unit's requirements for the project duration, but also provide greater flexibility for the arrangement of various procedures. It can effectively deal with the impact of weather, resources and other factors on the construction plan.

\subsection{Application of Fuzzy Mathematics in Green Building}

Wang Lina [73] used fuzzy recognition and fuzzy comprehensive evaluation methods to calculate the target cost and function coefficients by establishing a green building investment decision-making model based on value engineering, and then obtained the value coefficients of each plan. Compared with the traditional decision-making method that simply evaluates economic effects, the decision-making method based on value engineering can evaluate the design and implementation of green buildings more comprehensively and objectively. The results show that the combination of value engineering principles and fuzzy mathematics tools can better reflect the objective facts of things and make simple and feasible quantitative decisions. It solves the problem of considering only direct economic benefits but insufficient consideration of improving building functions and life-span economic benefits.

An Yuhua [74] uses value engineering and fuzzy comprehensive evaluation model to quantitatively evaluate the functions of each primary selection scheme of green buildings and estimate the additional cost, and finally determine the value function coefficient of each scheme to select the optimal scheme. The results show that this method can make green buildings have optimal choices at the beginning of the whole life cycle, analyze the value of green buildings from a macro perspective, and play a good role in paving the way for later construction and operation.

\section{Conclusions}

Through literature investigation, research and analysis, it is found that there are certain uncertainties or ambiguities in many aspects of construction project management. Through the use of fuzzy mathematics, the problem of fuzzy phenomena can be quantitatively analyzed, which has important significance in actual engineering. Provide theoretical basis. With the improvement of the management system, a single method of fuzzy mathematics can no longer meet the actual needs. It is more practical to carry out comprehensive quantitative and qualitative analysis of fuzzy phenomena by combining with other management methods. The combination of fuzzy mathematics with other management methods and computer application can simplify the complicated things, reduce subjectivity and improve the calculation speed. It further enables managers to be more efficient in management, and can quickly make decisions and deal with 
uncertainties or emergencies in a timely manner. At the same time, it can reduce the cost and improve the quality and economic benefits of the project construction.

In the process of actual construction project management, it is found that fuzzy mathematics is rarely applied in actual project engineering, and the theoretical research is mostly, and the project cases are relatively limited and cannot be better realistic. At the same time, studies have found that the combination of fuzzy theory and heuristic algorithms or meta-heuristic algorithms can make the research objective and improve the calculation speed, but there are few related studies in this area. The next step will focus on these two aspects, using fuzzy mathematics methods to judge, evaluate and make decisions on the research objects, so as to form a more effective management and decision-making system.

\section{Conflicts of Interest}

The authors declare no conflicts of interest regarding the publication of this paper.

\section{References}

[1] Cao, M. (2019) Construction Project Management. Tsinghua University Press, Beijing.

[2] Abdul-Rahman, H., et al. (2013) Design and Pilot Run of Fuzzy Synthetic Model (FSM) for Risk Evaluation in Civil Engineering. Journal of Civil Engineering and Management, 19, 217-238. https://doi.org/10.3846/13923730.2012.743926

[3] Antucheviciene, J., et al. (2015) Solving Civil Engineering Problems by Means of Fuzzy and Stochastic MCDM Methods: Current State and Future Research. Mathematical Problems in Engineering, 2015, Article ID: 362579. https://doi.org/10.1155/2015/362579

[4] Fayek, A.R. (2020) Fuzzy Logic and Fuzzy Hybrid Techniques for Construction Engineering and Management. Journal of Construction Engineering and Management, 146, Article ID: 04020064. https://doi.org/10.1061/(ASCE)CO.1943-7862.0001854

[5] Liu, F., et al. (2009) Improved Fuzzy Comprehensive Evaluation Model of Construction Engineering Quality.

[6] Liu, J.Y., et al. (2007) Study on Optimized-Select Model of Underground Engineering Reinforcement and Reconstruction Based on Grey Fuzzy Decision Making. 2007 IEEE International Conference on Grey Systems and Intelligent Services, Nanjing, 18-20 November 2007, 992-995. https://doi.org/10.1109/GSIS.2007.4443421

[7] Omishore, A. and Puklicky, L. (2011) Fuzzy Analysis of Civil Engineering Problems. 17 th International Conference on Soft Computing, Brno, 2011, 271-274.

[8] Shaheen, A.A., et al. (2009) Methodology for Integrating Fuzzy Expert Systems and Discrete Event Simulation in Construction Engineering. Canadian Journal of Civil Engineering, 36, 1478-1490. https://doi.org/10.1139/L09-091

[9] Zhu, G., et al. (2012) Fuzzy Comprehensive Evaluation of Civil Engineering Construction Safety Accident. In: Shao, Y., Hao, S., Luo, Y., Xing, J. and Liu, Z., Eds., Advanced Building Materials and Sustainable Architecture, PTS 1-4, Applied Mechanics and Materials (Volumes 174-177), Trans Tech Publications Ltd., Stafa-Zurich, 3448-3451. https://doi.org/10.4028/www.scientific.net/AMM.174-177.3448 
[10] Zuo, J. and Wu, X. (2010) Fuzzy Mathematics in Civil Engineering Application of Tender Offer.

[11] Wang, K.B. and Chang, L.B. (2020) Application of Fuzzy Mathematics in Construction Engineering Bidding-Comment on "Construction Engineering Bidding and Contract Management”. Industrial Construction, 50, 196.

[12] Yu, J.X., Xu, H.L., Li, Y.C. and Tan, Z.D. (2007) Quantitative Research on Construction Project Risk. Water Resources and Hydropower Technology, No. 10, 48$49+56$.

[13] Feng, W.M., Cao, Y.J. and Ren, H. (2003) Research on Civil Engineering Cost Estimation Method Based on Case-Based Fuzzy Reasoning. China Civil Engineering Journal, No. 03, 51-56.

[14] Zadeh, L.A. (1965) Fuzzy Sets. Information and Control, 8, 338-353. https://doi.org/10.1016/S0019-9958(65)90241-X

[15] Kerre, E. (1995) On the Evolution of the Mathematics of Fuzziness. In: Ruan, D., Ed., Fuzzy Set Theory and Advanced Mathematical Applications, Kluwer Academic Publishers, Boston, 1-34. https://doi.org/10.1007/978-1-4615-2357-4_1

[16] Kerre, E. and Mordeson, J.N. (2005) Ahistorical Overview of Fuzzy Mathematics. New Mathematics and Natural Computation, 1, 1-26. https://doi.org/10.1142/S1793005705000032

[17] Mordeson, J.N. (2011) Zadeh's Influence on Mathematics. Scientia Iranica, 18, 596601. https://doi.org/10.1016/j.scient.2011.04.012

[18] Mo, Z., Wen, S.L. and Xu, B. (1998) Review of Fuzzy Mathematics Theory and Its Application. Journal of Sichuan Normal University, No. 4, 330-335.

[19] Yang, Y.F., Zeng, F., Jin, X. and Hong, Y. (2006) Application of Fuzzy Mathematics in Civil Engineering. Mining Express, No. 4, 27-28.

[20] Yang, Q. and Wei, Y. (2011) Risk Evaluation of Highway Engineering Project Based on the Fuzzy-AHP. Proceedings International Conference on Graphic and Image Processing (ICGIP 2011), Volume 8285, 82852O. https://doi.org/10.1117/12.913584

[21] Zhu, H. and Hu, J. (2011) Research on Model of Comprehensive Fuzzy Assessment of Projects Post Evaluation. International Conference on Civil Engineering and Building Materials, Kunming, 26-28 July 2011, 566-570. https://doi.org/10.4028/www.scientific.net/AMR.261-263.566

[22] Xie, X.H. and Zhou, Y. (2003) Research on Project Evaluation Method Based on Fuzzy Mathematics. Journal of Anhui Institute of Architecture and Industry (Natural Science Edition), No. 2, 75-78.

[23] Zhong, Y., et al. (2018) Uncertainty Analysis and Resource Allocation in Construction Project Management. Engineering Management Journal, 30, 293-305. https://doi.org/10.1080/10429247.2018.1492269

[24] Wang, X., et al. (2019) An Interval Risk Assessment Method and Management of Water Inflow and Inrush in Course of Karst Tunnel Excavation. Tunnelling and Underground Space Technology, 92, Article ID: 103033. https://doi.org/10.1016/j.tust.2019.103033

[25] Meng, G., et al. (2020) Risk Assessment of Deep Foundation Pit Construction Based on Analytic Hierarchy Process and Fuzzy Mathematics. Advances in Civil Engineering, 2020, Article ID 8840043. https://doi.org/10.1155/2020/8840043

[26] Xu, S., et al. (2012) The Research of Construction Project Risk Management Based on Monte Carlo Method and Fuzzy Mathematics. In: Zhong, S. and Qu, X.L., Eds., Smart Materials and Intelligent Systems, Advanced Materials Research (Volume 442), 
Trans Tech Publications Ltd., Stafa-Zurich, 341-345. https://doi.org/10.4028/www.scientific.net/AMR.442.341

[27] Geng, D., et al. (2013) Optimization Study of Subway Station Underground Excavation Construction Method Based on Fuzzy Theory. In: Zhao, S., Xie, Y.M., Liu, H. and Gao, D., Eds., Civil Engineering, Architecture and Sustainable Infrastructure II, PTS 1 and 2, Applied Mechanics and Materials (Volumes 438-439), Trans Tech Publications Ltd., Stafa-Zurich, 1015-1019.

https://doi.org/10.4028/www.scientific.net/AMM.438-439.1015

[28] Chang, F. (2012) International Engineering Risk Management-Based on Fuzzy Mathematics. University of International Business and Economics, Beijing.

[29] Zheng, Z.F. and Zhou, Z. (2006) Research on the Application of Fuzzy Mathematics in Engineering Project Risk Identification. Journal of Chongqing Jiaotong University, No. 2, 122-124.

[30] Wang, Y. (2009) The Application of Fuzzy Mathematics in the Risk Assessment of Construction Projects. Jiangsu Architecture, No. 2, 76-78.

[31] Niu, X.F. (2008) Research on PPP Project Financing Risk Index System and Fuzzy Comprehensive Analysis Method. Chongqing University, Chongqing.

[32] Xu, C.Y. (2009) Research on Risk Assessment of Construction Projects Based on Fuzzy-AHP. Shanxi Architecture, 35, 184-185.

[33] Wei, W. and Li, Z.G. (2009) Application of Fuzzy Comprehensive Evaluation Method in Risk Evaluation of Construction Projects. Fujian Building Materials, No. 3, 106-107.

[34] Lu, W.L. (2012) Application of Comprehensive Evaluation Method Based on Fuzzy Grey Theory in Highway Construction Projects. Journal of Hunan Institute of Engineering (Natural Science Edition), 22, 76-80.

[35] Zhu, M.M. (2010) Project Risk Assessment Based on Fuzzy Analytic Hierarchy Process. Science and Technology Management Research, 30, 214-217.

[36] Guan, J. and Li, W.H. (2000) Research on the Risk Decision-Making Method of Construction Project Bidding Price. Technoeconomics and Management Research, No. 4, 39-40.

[37] Xie, M., Ni, G.D. and Wang, J.P. (2010) Research on Risk Evaluation of Agent Construction Unit Based on Fuzzy Analytic Hierarchy Process. Journal of Engineering Management, 24, 262-266.

[38] Feng, G.Y. (2010) Application of Fuzzy Mathematics in Audit Risk Assessment. Hebei Enterprise, No. 6, 78.

[39] Fan, Z.-Q., et al. (2012) Fuzzy Comprehensive Evaluation Based on Environmental Effect of Karst Tunnel Engineering. 2012 International conference on Fuzzy Theory and Its Applications (iFUZZY2012), Taichung, 16-18 November 2012, 388-393. https://doi.org/10.1109/iFUZZY.2012.6409737

[40] Zhang, C.Q. (2013) Research on Building Safety Management Based on Fuzzy Comprehensive Evaluation. Journal of Taiyuan Urban Vocational and Technical College, No. 8, 172-174.

[41] Guo, J.J. (2015) Research on Safety Evaluation of High-Rise Building Construction Based on Fuzzy Mathematics and BP Neural Network. Hebei University of Engineering, Handan.

[42] Zhang, Q.Y. (2014) Application Research on Comprehensive Evaluation System for Fire Safety of Super High-Rise Buildings. East China University of Science and Technology, Shanghai. 
[43] Li, T.T. (2013) Research on the Safety Management System and Risk Evaluation Method of Mountain Highway Construction. Chang'an University, Chang'an.

[44] Zhang, W. (2013) Research on Safety Evaluation of Temporary Structure of Bridge Construction. Chongqing Jiaotong University, Chongqing.

[45] Zhao, D.G. (2011) Safety Risk Analysis of Subway Construction Based on Fault Tree Method. Huazhong University of Science and Technology, Wuhan.

[46] Zan, Y.G. and Hou, X.L. (2014) Identification and Prevention of Safety Hazards in Construction Engineering Based on Fuzzy Recognition. Construction Economy, 35, 126-129.

[47] Wang, W., et al. (2013) Fuzzy Evaluation Method in the Application of the Engineering Bidding. In: Sung, W.P., Kao, J.C.M. and Chen, R., Eds., Frontiers of Manufacturing Science and Measuring Technology III, PTS 1-3, Applied Mechanics and Materials Vol. 401, Trans Tech Publications Ltd., Stafa-Zurich, 2252-2255. https://doi.org/10.4028/www.scientific.net/AMM.401-403.2252

[48] Li, D. and Dong, Z.-G. (2012) The Fuzzy Evaluation Model for Opportunity Choosing in Engineering Project Bidding. 2012 International Conference on Management Science \& Engineering, Dallas, 20-22 September 2012, 353-358. https://doi.org/10.1109/ICMSE.2012.6414205

[49] Li, D. and Dong, Z.G. (2014) Research on the Decision-Making of Engineering Project Bidding Based on Fuzzy Mathematics. Journal of Gansu Sciences, 26, 146-150.

[50] Liu, E.L., Wang, J. and Luo, G. (2003) Decision-Making Method for Project Bidding Based on Fuzzy Logic. China Civil Engineering Journal, No. 3, 57-63.

[51] Wang, Z.X. (1986) Application of Fuzzy Mathematics in Bidding and Bidding in Civil Engineering. China Civil Engineering Journal, No. 2, 88-92.

[52] Ruan, L.F. and Wen, H.Z. (2000) Application of Fuzzy Comprehensive Evaluation in Project Bidding Price. Construction Economics, No. 2, 32-35.

[53] Wang, J., Li, L.Z. and Ma, T. (2005) Project Bidding Decision-Making Method Based on Fuzzy Comprehensive Evaluation. National Defense Traffic Engineering and Technology, No. 3, 30-33.

[54] Peng, H., Han, C. and Zhang, Z.L. (2014) Research on Construction Engineering Bid Evaluation Methods Based on AHP and Fuzzy Mathematics. Journal of Chongqing University of Science and Technology (Natural Science Edition), 16, 102-105.

[55] Wang, C. and Wei, N. (2014) Study and Application of the Life-Cycle Cost Control Model of Water Conservancy and Hydropower Project Based on Entropy and FAHP. In: Zhang, H., Han, M. and Zhao, X.J., Eds., Advanced Development of Engineering Science IV, Advanced Materials Research (Volume 1046), Trans Tech Publications Ltd., Stafa-Zurich, 564-568. https://doi.org/10.4028/www.scientific.net/AMR.1046.564

[56] Zhang, C.S. and Sun, H. (2015) Research on Construction Project Cost Based on Fuzzy Mathematics. Value Engineering, 34, 16-18.

[57] Han, M.L. (2012) Application of Fuzzy Neural Network in Highway Engineering Cost Estimation. Science and Technology Information, No. 5, 166.

[58] Ge, J. (2013) Talking about the Estimation Model of Project Cost. Henan Science and Technology, No. 14, 244-245.

[59] Zhang, G.Q. and Zhang, H.L. (2007) A Review of Domestic and Foreign Engineering Cost Estimation Models. Construction Technology, 36, 396-399.

[60] Jia, Y.M., Tu, M. and Dong, J.J. (2010) Research on the Application of Fuzzy Mathematics Principles to Quickly Estimate Engineering Costs. Shanxi Architecture, 
36, 277-279.

[61] Zheng, Z.L., Deng, S.J., Gao, S.X., Tan, D.J. and Zhong, K.L. (2001) Fuzzy Determination of Construction Cost. Journal of Chongqing University (Natural Science Edition), No. 1, 55-58.

[62] Wang, B.Z. (2014) Research on the Application of Fuzzy Mathematics in the Rapid Evaluation of Municipal Engineering. Chinese and Foreign Architecture, No. 5, 109110.

[63] Wang, H., Yang, H.S. and Hu, Y.T. (2012) Construction of Investment Estimation Model for Water Conservancy Projects Based on Fuzzy Exponential Smoothing Method-Take F Hydropower Station Project to Be Built in Yunnan Province as an Example. Project Management Technology, No. 8, 31-34.

[64] Liang, L.L. and Li, L.J. (2011) Research on Fuzzy Forecasting Technology of Reasonable Engineering Cost. Journal of Taiyuan University of Technology, 42, 88-91.

[65] Zhao, H.B. (2013) Construction Project Contract Management System Based on Fuzzy Mathematics Method. Science and Technology and Enterprise, No. 13, 57-58.

[66] Li, X.W. (2014) Fast Prediction of Engineering Claims Based on Fuzzy Comprehensive Theory. Statistics and Decision, No. 6, 180-182.

[67] Bian, Y.B., Yang, J.J. and Liu, B. (2011) Research on Risk Evaluation of Project Settlement Disputes Based on Fuzzy Analytic Hierarchy Process. Building Technology Development, 38, 66-67, 71.

[68] Xu, F.Z. and Lu, H.M. (2014) Fuzzy Optimization of Project Duration-Cost-Quality. Project Management Technology, 12, 52-54.

[69] Wu, P. (2005) Research on the Application of Construction Quality Control and Evaluation Methods for Building Engineering. Xi'an University of Architecture and Technology, Shaanxi.

[70] Deng, D.X. (2008) Construction Project Quality Management and Application Research. Southwest Jiaotong University, Chengdu.

[71] Song, Y. (2010) Research on Construction Quality Management and Control of Residential Engineering. Shandong University, Jinan.

[72] Liu, Z., Zhao, S.L. and Wang, X.Y. (2012) Research on Construction Project Schedule Optimization Based on Fuzzy Evolutionary Algorithm. Journal of Hebei Agricultural University, 35, 98-101, 110. https://doi.org/10.1088/1475-7516/2012/01/021

[73] Wang, L.N. and Yuan, Y.B. (2011) Research on Green Building Investment Decision-Making Based on Value Engineering. Value Engineering, 30, 26-27.

[74] An, Y.H. and Yang, H.L. (2015) Research on Green Building Investment Decision Based on Value Engineering and Fuzzy Mathematics Theory. Journal of Jilin Jianzhu University, No. 3, 84-88. 